\title{
Online Food Ordering System
}

\author{
Trupthi B, Rakshitha Raj R, J B Akshaya, Srilaxmi C P
}

\begin{abstract}
An Online Food Ordering System is proposed here which simplifies the food ordering process. The proposed system shows an user interface and update the menu with all available options so that it eases the customer work. Customer can choose more than one item to make an order and can view order details before logging off. The order confirmation is sent to the customer. The order is placed in the queue and updated in the database and returned in real time. This system assists the staff to go through the orders in real time and process it efficiently with minimal errors.
\end{abstract}

Index Terms - PHP, MYSQL, WAMPP, CSS, APACHE, NETBEANSIDE, EMENUCARD, PERL/PHP/PYTHON.

\section{INTRODUCTION}

The labour rates are increasing steadily year on year thus making it difficult to find employees. The food industry is highly labour intensive and the biggest expense in the food industry is the cost of employing the right kind of people to do the work. One of the ways to reduce this expense is to use modern technology to replace some of the jobs done by human beings and make machines do the work. Here we propose an "Online Food Ordering System" that has been designed for Fast Food restaurant, Take-Out or College Cafeterias. The system can also be used in any food delivery industry. This simplifies the process of food ordering for both the customer and the restaurant, as the entire process of taking orders is automated.

\section{LITERATURE REVIEW}

Various case studies have highlighted the problems faced while setting up a restaurant $[1-5]$. Some of the problems found during the survey in the existing system are listed below:

- To place the orders customer visits the restaurant, checks the menu items available in the restaurant, and chooses the items required, then places the order and then do the payment. This method demands manual work and time on the part of the customer.

- When the customer wants to order over the phone, customer is unable to see the physical copy of the menu available in the restaurant, this also lacks the verification that the order was placed for the appropriate menu items.

- Every restaurant needs someone or the other to take

Revised Manuscript Received on July 10, 2019

Trupthi B, Department of Electronics and Communication Engineering, Vidyavardhaka College of Engineering, Mysuru Karnataka. India. (E-mail: trupthibhyregowda@gmail.com)

Rakshitha Raj R, Department of Electronics and Communication Engineering, Vidyavardhaka College of Engineering, Mysuru, Karnataka. India. (E-mail: rakshitharaj22@gmail.com)

J B Akshaya, Department of Electronics and Communication Engineering, Vidyavardhaka College of Engineering, Mysuru, Karnataka. India. (E-mail: akshayajb2010@gmail.com)

Srilaxmi C P, Department of Electronics and Communication Engineering, Vidyavardhaka College of Engineering, Mysuru, Karnataka. India. (E-mail: srilaxmi.kowshik@gmail.com) the order personally or over phone, to offer the customer a rich experience and even to process the payment.

\section{METHODOLOGY:}

The simulation first starts with the customer entering his/her credentials (name, ID and password). Once that has been verified, the customer can place an order specifying the quantity of the food required. Now we get a window that displays the order number, customer ID, food name, price and quantity. Once the customer finalizes his/her order, they are redirected to the payment window where the total price is displayed and the customer can select the payment method of their choice and then the customer gets a message of confirmation of order. The block diagram and the ER Diagram of the proposed Online Food Ordering System is given in Figure 1 (a) and (b).

The above mentioned simulation flow is with respect to the customer's point of view. Now if you are an admin, you can select the normal login option and enter the admin credentials (email ID and password). Once you enter the admin portal, you get the option of adding food, deleting food or updating food. Any option of choice leads you to the food menu. Once the selected operation is carried out, the end result, i.e, the added food or the updated food list is displayed and if you have deleted a food, that particular food disappears from the main menu.

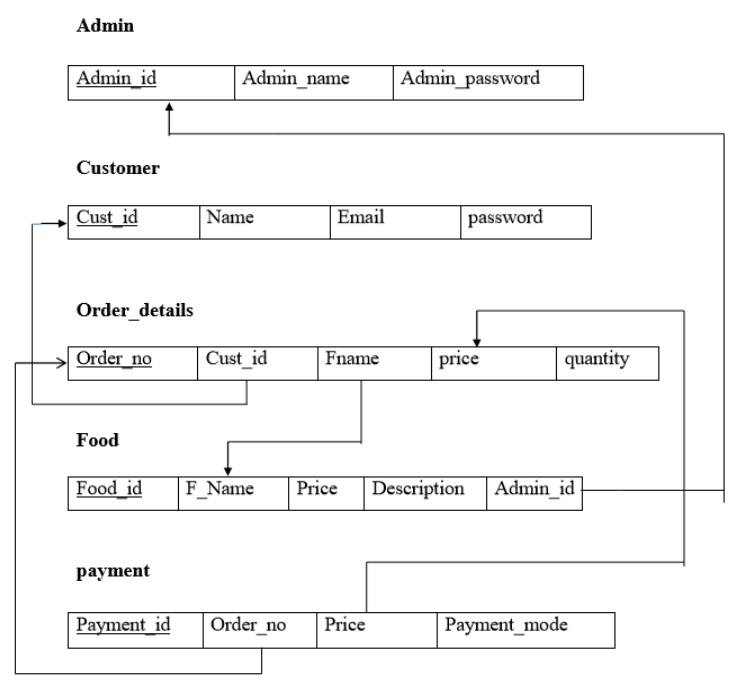

(a). 


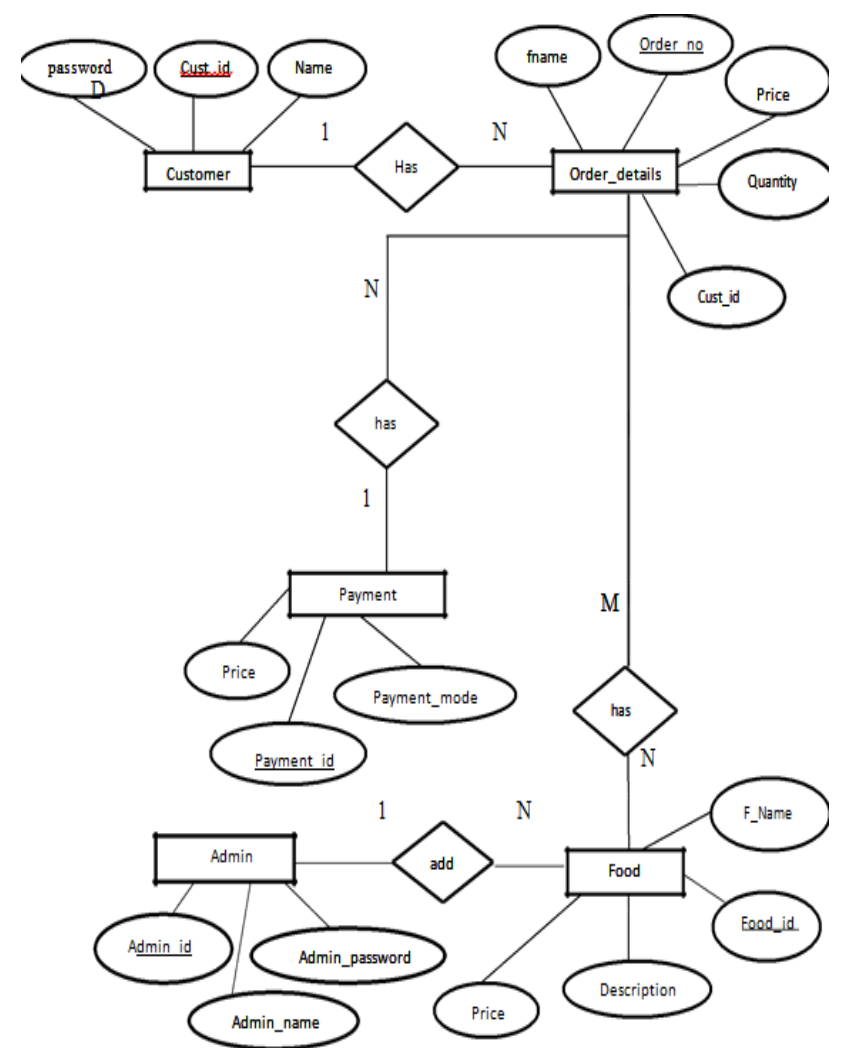

(b)

Fig. 1 (a) The block diagram of the Online Food Ordering System, (b) The ER Diagram of the Online Food Ordering System.

\section{SOFTWARE REQUIREMENTS}

PHP: Hypertext Pre-processor is language which began for developing web applications, is also a general-purpose programming language. PHP code is executed in a given order where it is first started by a PHP interpreter, which is then implemented as a web server module. The output of both of the interpreted and executed PHP code is combined by web server, which may be any type that is associated with the created web page [6].

MySQL: It is an open source relational database management system (RDBMS). MySQL is the central component of the WAMP open-source web application software stack. WAMP is an acronym for "Windows, Apache, MySQL, [7] and Perl/PHP/Python". From source code MySQL can be built and installed manually, but it is always installed from a binary package due to customization. Although further steps is required to alert the security and optimization settings.

\section{HARDWARE REQUIREMENTS}

A desktop computer with Intel Core i3 64 bit processor and Graphic card 1 GB RAM, and Microsoft Windows 10 operating system was used.

\section{RESULTS}

Following are the results that one can draw from this system:

i. People can successfully order the food using the proposed system. ii. There will be a lesser requirement of staff at the back counter.

iii. The system will help in reduction of labour cost involved and also reduces the space required to set up cafeterias in the restricted area.

iv. As it is an automated system it is less probable to make any mistakes.

v. The customers can avoid the long queues at the counter, with a reasonable speed of execution and maximum throughput.

Figures 2 (a) - (e) show the snap shot of various stages of the food ordering system on the mobile App.

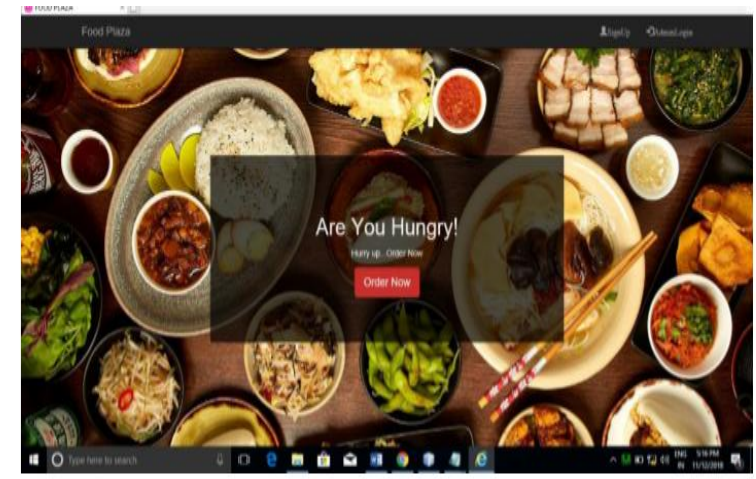

Fig 2 (a). The above snapshot shows the index page of Food Plaza, which provides various navigation buttons to reach other page.

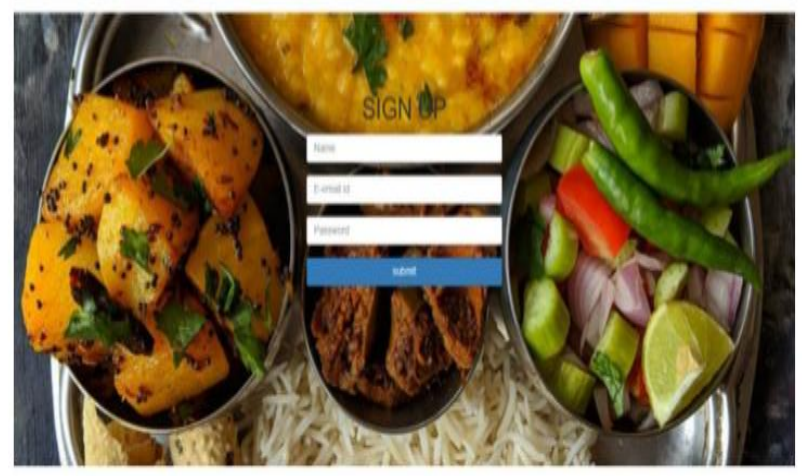

Fig 2 (b). The above snapshot shows the signup page and helps the new user to register in order to make order.

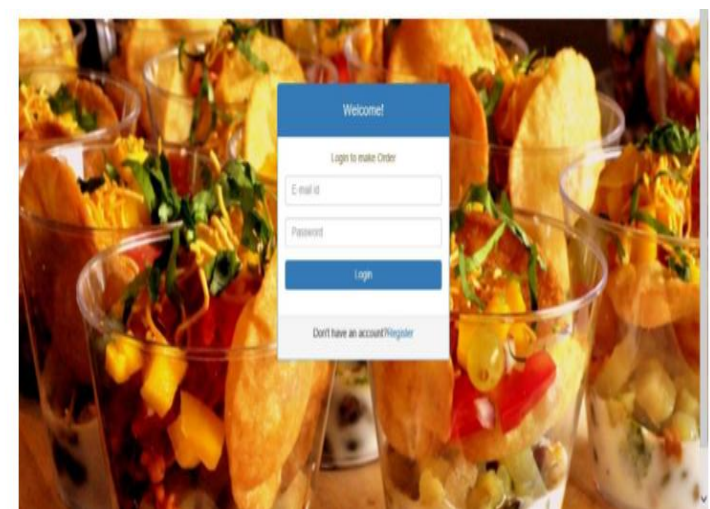

Fig 2 (c). The above snapshot shows the login page through this page user can login to make purchase.

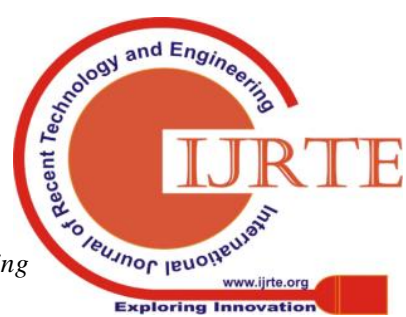




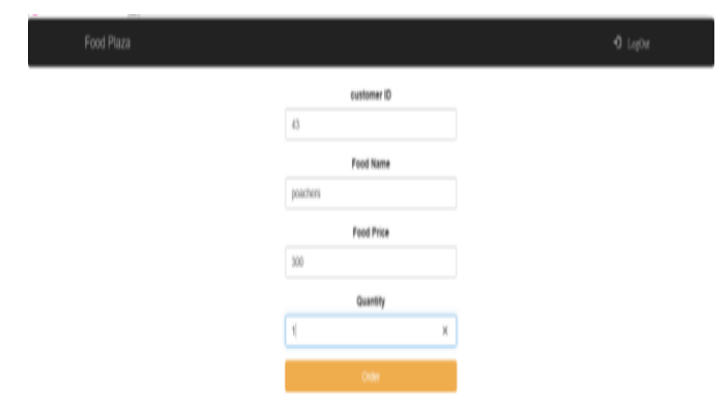

Fig 2 (d). This is the snapshot of order page through this page customer can place the order.

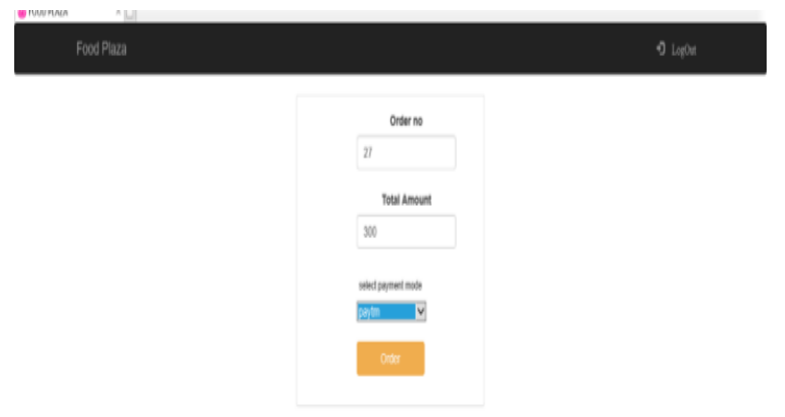

Fig 2 (e). This is the snapshot of payment page through which customer can pay the bill.

\section{DISCUSSION}

With the help of this system, people can easily order the food. It can also ensure that the people do not waste their precious time and use their time productively in the other works. In long run, this will ensure that it helps to reduce labour cost. This system proves to be more cost effective and reliable over other systems. This system is difficult to forge or cheat when compared to other systems in terms of payment for the food. It is very easy to use and has least maintenance. It does not require any human intervention and thus can be called fully automated. There isn't any limitations as such for this system, however one needs to take care of the smaller parameters like server breakdown while this system is implemented.

\section{CONCLUSION}

An online food ordering system is developed where the customers can make an order for the food and avoid the hassles of waiting for the order to be taken by the waiter. Using the application, the end users register online, read the E-menu card and select the food from the e-menu card to order food online. Once the customer selects the required food item the chef will be able to see the results on the screen and start processing the food. This application nullifies the need of a waiter or reduces the workload of the waiter. The advantage is that in a crowded restaurant there will be chances that the waiters are overloaded with orders and they are unable to meet the requirements of the customer in a satisfactory manner. Therefore by using this application, the users can directly place the order for food to the chef online.

In conclusion an online food ordering system is proposed which is useful in small family run restaurants as well as in places like college cafeteria, etc. This project can later be expanded on a larger scale. It is developed for restaurants to simplify their routine managerial and operational task and to improve the dining experience of the clients. This also helps the restaurant owners develop healthy customer relationships by providing reasonably good services. The system also enables the restaurant to know the items available in real time and make changes to their food and beverage inventory based on the orders placed and the orders completed.

\section{ACKNOWLEDGEMENT}

The authors express gratitude for the advice and help in preparing the manuscript provided by Accendere Knowledge Management Services Pvt Ltd.

\section{REFERENCES}

1. Awojide, Simon, I. M. Omogbhemhe, O. S. Awe, and T. S Babatope, "Towards the digitalization of Restaurant Business Process for Food Ordering in Nigeria Private University: The Design Perspective. A Study of Samuel Adegboyega University Edo State Nigeria,” Int. J. Sci. Res. Publ., vol. 8, no. 5, pp. 46-54, 2018.

2. O. I. Mike and A. Simon, "Towards the Digitalization of Hotel Business in Nigeria: The Design Perspective," vol. 8, no. 2, pp. 1175-1178, 2017.

3. Adithya. R., A. Singh, S. Pathan, and V. Kanade, "Online Food Ordering System,” Int. J. Comput. Appl., vol. 180, no. 6, pp. 22-24, 2017.

4. Varsha Chavan, Priya Jadhav, Snehal Korade, Priyanka Teli, "Implementing Customizable Online Food Ordering System Using Web Based Application", International Journal of Innovative Science, Engineering Technology(IJISET) 2015.

5. Patel, Mayurkumar, "Online Food Order System for Restaurants" (2015). Technical Library. Paper 219.

6. php code [online] available at www.w3schools.com

7. mysql code [online] available at www.stackoverflow.com 